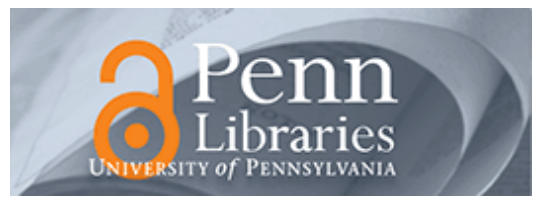

Studies in Visual Communication

Volume 6

Issue 3 Fall 1980

Article 2

1980

\title{
Sol Worth and the Study of Visual Communications
}

Larry Gross

\section{Recommended Citation}

Gross, L. (1980). Sol Worth and the Study of Visual Communications. 6 (3), 2-19. Retrieved from https://repository.upenn.edu/svc/vol6/iss3/2

This paper is posted at ScholarlyCommons. https://repository.upenn.edu/svc/vol6/iss3/2

For more information, please contact repository@pobox.upenn.edu. 
Sol Worth and the Study of Visual Communications

This contents is available in Studies in Visual Communication: https://repository.upenn.edu/svc/vol6/iss3/2 


\section{Sol Worth and the Study of Visual Communications Larry Gross}

The central thread that runs through Sol Worth's research and writings is the question of how meaning is communicated through visual images. ${ }^{1}$ Coming to academic life after careers in painting, photography, and filmmaking, Worth was imbued with the conviction that visual media were forms of communication that, while fundamentally different from speech, could and must be seriously examined as ways human beings create and share meanings. Focusing on film he began with the question, "What does a film communicate, and how does this process work?" (1966:322). The answers he began with grew out of his practice as a teacher of film.

\section{Teaching Film as Communication}

In Worth's initial experience in teaching film, as Fulbright Professor in Finland (1956-1957), he had utilized a method he later described as follows: "The teacher would make a film; the students would work along with him, learning and doing at the same time. Class discussions would be held in which the various aspects of the film were developed and demonstrated" (1963:54). The film he made during this process of teaching was Teatteri, now in the permanent collection of the Museum of Modern Art. When he came to the Annenberg School of Communications at the University of Pennsylvania to set up and teach a course in documentary film, however, Worth adopted a different approach: the students would make a film. This choice was decisive in orienting him toward questions and perspectives that influenced all his subsequent work. It led Worth to consider problems few film scholars had posed or pursued.

The most immediate consequence of this pedagogical decision was a concern over the inexperience of his students:

The young men and women in my class were bright, but they had never before made a film. They had never used a camera, edited a shot, or written a script. There was not enough time. And I was worried. If I made a film, I could control it; if I let the students make their own films, they could fail. The films might be bad or unfinished, the cameras and equipment might be ruined, film might be wasted. [1963:55]

Larry Gross is Associate Professor of Communication at The Annenberg School of Communication, University of Pennsy/vania, and is co-editor of Studies in Visual Communication.
This concern proved unfounded. The students succeeded in making films and the workshop technique seemed to engage them in the process Worth deemed appropriate to a school of communications:

The process of changing back and forth from conception as paramount, to the actual visual document as paramount, seems to me the key learning process in the Documentary Film Workshop. It is the way in which the students learn to see. It is the process by which they train themselves to find a meaningful visual image in relation to a concept which is usually literary or philosophical in nature. The purpose of the Workshop is not to produce films (this is our pleasure), but rather, to provide an environment in which students learn to see filmically; to provide an environment where they can learn about the techniques and the thinking necessary to communicate ideas through the filmed image. [1963:56f]

It was the final stage in the Workshop, however, that led Worth to the next set of questions. When the films were completed, they were screened before an audience of students, friends, and faculty. "It is in the period after the lights go on, when the comments are made, that the student begins to know how very complex and difficult the art of film communication is" (1963:57). The students weren't alone, as Worth himself became increasingly intrigued by a pattern he found in the responses of diverse audiences to the films made by his students:

The greatest involvement, identification, and understanding seems to come from the young and the untrained. The greatest hostility and incomprehension seems to come from the adult professional in the communication fields.... Adolescents find these films easier to understand than do adults. [1965:12]

\section{The Bio-Documentary}

In trying to make sense of this unexpected pattern of responses Worth first clarified the nature of the films he was screening. He realized that the inexperience of the student filmmakers (their lack of socialization in traditional film codes), and his insistence that "the subject matter evolves from the student's own interests and experiences" (1963:56), lead to a particularly subjective kind of film. Worth called this kind of film "bio-documentary":

a film that can be made by a person who is not a professional filmmaker; or by someone who has never made a film before. It is a film that can be made by anyone with enough skill, let's say, to drive a car; by a person of a different culture, or a different age group, who has been taught in a specific way to make a film that helps him to communicate to us, the world as he sees it, and his concerns as he sees them. [1964:3] 
In posing the concept of a bio-documentary Worth was clearly concerned with analogies between subjective films and dreams as forms of visual imagery:

A bio-documentary is a film made by a person to show how he feels about himself and his world. It is a subjective way of showing what the objective world that a person sees is really like. .... In addition . . . it often captures feelings and reveals values, attitudes, and concerns that lie beyond the conscious control of the maker. [1964:3]

But it wasn't enough to see the bio-documentary as a subjective, individual statement by a novice filmmaker. That might explain why adults could not "understand" these films, and especially why "hostility seems to be found most frequently among filmmakers, film critics, and communications professionals ... (e.g. 'I think you are intellectually irresponsible to teach young people to make films like this... I think the whole thing is a hoax

.')" (1965:7). After all, it is hardly a novel observation that those most engaged with a set of conventions in art are the most outraged at innovations or variations that ignore, challenge, or undermine these conventions.

It still remained to ask why young viewers responded with enjoyment and understanding; after all, even if they were not professionals, they were used to seeing "conventional" films. Worth decided that there was something in the subject matter and the structure of the films that was comprehensible to young viewers because it was closer to their way of talking and thinking. In particular he felt that the films used ambiguities and hints in a fashion that adults were no longer comfortable with, but which younger viewers found "safer and more comfortable for certain themes than [they] would an outright statement" (1965:18).

Although he himself probably did not see the implications of his inquiries at this point, Worth was laying some of the foundations for an important analytic shift that gradually became explicit in his thinking. I believe that he was already expressing some uneasiness with the psychological approach noted above - e.g., bio-documentaries as "dream-like" revelations of the unconscious. Although much of Worth's research on film during the rest of the 1960 s is clearly dominated by the psychological model of individual expression, he increasingly focused his attention (often simultaneously, even contradictorily) on film as cultural communication. Even at this point, then, Worth was beginning to formulate two related sets of questions which he pursued for the rest of his life.

First, he was led to tackle the question of how meaning can be communicated in various modes and media: are visual images in general, and film in particular, better understood in light of an overall theory of communication as symbolic behavior; and what would this theory look like?
Second, he understood that his experience with novice filmmakers suggested a radical innovation in the way the film medium could be used as a research tool. If anyone could be taught to make a film that reflected his or her own world view, and the values and concerns of his or her group, then the direction of the film communication process could be reversed. This meant using the medium "to see whether the visual world offers a way of communication that can be used not only for us to communicate to them, but so that we might make it easier for them to talk to us" (1965:19).

Although these two sets of questions were pursued in tandem, and their interconnections formed the basis of much of Worth's intellectual development, it will be necessary for the purpose of exposition to discuss them separately.

\section{The Navajo Project}

The first fruits of the bio-documentary approach and the realization of the potential it offered for communication by "them to talk to us" were not long in coming. In his first exposition of the bio-documentary film concept, at the 1964 Meeting of the Society for Applied Anthropology, Worth already saw the possibility of using this method to explore the world view of another culture.

In a documentary film about the Navajo you look for an objective representation of how they live as seen by an outsider. In a Bio-Documentary about the Navajo, the film would be made by a Navajo. One would not only look to see how the Navajo live, but one would also look to see how a Navajo sees and structures his own life and the world around him. [1964:5] ${ }^{2}$

In this capsule "proposal" for a research project, Worth later realized he was obeying Malinowski's injunction that "the final goal, of which an Ethnographer should never lose sight. . . is, briefly, to grasp the native's point of view, his relation to life, to realize his vision of his world" (1922:25). In this context, it is interesting to note Worth's sensitivity to one of the most important but often neglected problems in anthropological theory and practice: the influence of the researcher's own values and biases. The proposed use of the bio-documentary approach was, to use a term that achieved currency in later years, reflexive:

Of course no view by one man of another is entirely objective. The most objective documentary film, or report, includes the view and values of the maker. The standard documentary film tries, however, to exclude as much as possible of this personal value system. The Bio-Documentary, on the other hand, encourages and teaches the filmmaker to include and to be concerned with his own values. . . . The Bio-Documentary method teaches the maker of the film to search for the meaning he sees in his world and it encourages the viewer to continue that search by comparing his values with the values expressed by the filmmaker in the film. [1964:5] 
This interest in what "other people had to say about themselves through film, and how one could teach them to say it" (Worth and Adair 1972:30) led to the Navajo Filmmakers Project conducted in the summer of 1966 by Worth in collaboration with John Adair, an anthropologist long familiar with the Navajo, and assisted by Richard Chalfen, then a graduate student working with Worth.

The project addressed a series of research objectives and issues:

1 To determine the feasibility of teaching the use of film to people with another culture. [Worth and Adair 1970:11]

2 To find out if it was possible to systematize the process of teaching; to observe it with reference to the maker, the film itself, and the viewer; and to collect data about it so as to assist other ongoing research exploring the inference of meaning from film as a communicative "language." [ibid.:12]

3 [To test the hypothesis that] motion picture film, conceived, photographed, and sequentially arranged by a people such as the Navajo would reveal something of their cognition and values that may be inhibited, not observable, or not analyzable when investigation is totally dependent on verbal exchange especially when it must be done in the language of the investigator. [ibid.]

4 [To] create new perspectives on the Whorfian hypothesis, work on which has for the most part been limited to linguistic investigation of cognitive phenomena. Through cross-cultural comparative studies using film as a mode of visual communication relationships between linguistic, cognitive, cultural and visual phenomena might eventually be clarified. [Worth and Adair 1972:28]

5 [To see whether] the images, subjects and themes selected and the organizing methods used by the Navajo filmmakers would reveal much about their mythic and value systems. [It was] felt that a person's values and closely held beliefs about the nature of the world would be reflected in the way he edited his previously photographed materials. [ibid.]

6 To study the process of "guided" technological innovation and observe how a new mode of communication would be patterned by the culture to which it is introduced. [Worth and Adair 1970:12]

The Navajo project was enormously successful. The films made by the Navajo filmmakers were widely screened and discussed as "a breakthrough in crosscultural communications" (Mead 1977:67). Worth's involvement with anthropology deepened after the completion of the project and the publication of its results (Worth and Adair 1967, 1970, 1972). He became increasingly identified with the revitalization of a subfield, the anthropology of visual communications, a term he proposed as an alternative to the earlier term visual anthropology.

Worth felt that most anthropologists viewed film and photography only as ways to make records about culture (usually other cultures) and failed to see that they could be studied as phenomena of culture in their own right, reflecting the value systems, coding patterns, and cognitive processes of their maker. His experience with biodocumentary films had clarified this distinction for him and he saw it as crucial to the understanding of visual communications. Pursuing this distinction leads to three issues which Worth was concerned with:

1 The denial of the possibility of an objective, value-free film record and the assertion of an inherent cultural bias of a filmmaker raises serious questions about the way we all view photographic images, and our tendency to accept them as evidence about the external world. In particular Worth was disturbed by the lack of understanding and sophistication on the part of anthropologists regarding their own use of visual image technologies.

2 The use of these technologies to record the lives of others for our purposes, and the purveying to others of our own cultural products and technologies (again, usually for our own profit), raise serious ethical issues about the power and the use of media which we ourselves do not adequately understand.

3 There is a need to understand the nature of film as a medium of communication-is there a film code and what are its properties?

I will begin with the last of these, which takes us back to the question of how meaning is communicated through film.

\section{Film as Communication}

In the process of analyzing the early bio-documentary films made by his students, Worth had realized that although they were subjective they were not wholly idiosyncratic. In his discussion of these films he noted that "the films all employ similar grammars (in the sense of editing devices and filmic continuities) . . grammars of argot rather than of conventional speech" (1965:18). As I have noted, the decision to view these films as social rather than merely individual expressions led to the question of whether there were underlying rules for the shaping and sharing of meanings in film.

Worth began by employing a communications theory model, in which film is seen as "a signal received primarily through visual receptors, which we treat as a message by inferring meaning from it" (ibid.:323, emphasis in original). The implications of this last point were to become increasingly central in Worth's work, but he already was insisting that "there is no meaning in the film itself . . . the meaning of a film is a relationship between the implication of the maker and the inference of the audience" (ibid.). But how did this process of implying and inferring meanings actually occur? In two of his early papers 
(1966, 1968) Worth laid out an initial model, some of which was retained and developed in future work, and some of which was modified or discarded as his thinking progressed.

Because much of the model of film communication presented in these papers is repeated in the paper "The Development of a Semiotic of Film" (1969), I will briefly discuss some aspects of the earlier papers which were less prominent in the later effort. In addition, I will focus on what I feel are the weaknesses as well as the achievements of Worth's approach as represented by all three of these papers.

In these initial papers Worth drew heavily upon a psychological framework for understanding film, again making an analogy to the dream as an "intrapersonal mode of communication through image events in sequence. The film is a similar mode of communication but most often extended to the interpersonal domain" (1968:3). He proceeded to outline "an intuitive experiential model" of film as a process which begins with a "Feeling Concern. . to communicate something," a concern "which many psychologists feel is almost a basic human drive" (1966:327). This feeling concern should not be seen as an explicit message that one wants to communicate; it "is most often imprecise, amorphous, and internalized. It cannot be sent or received as a film in this internalized, 'feeling' state" (1968:4).

Here Worth makes a further point which he did not pursue at the time, but which can be seen as an early indicator of what later became an important part of his view of communicative phenomena:

Obviously, inferences can be made about internal feeling states by observing a subject's gestures, body movements, and so forth. . . . [However] there is an important distinction which must be made between the inferences we make from a person's own behavior, which can have a great variety of reasons explaining and motivating them, and the inferences we make from a coded expression in linguistic or paralinguistic form whose purpose is primarily communicative. [ibid.]

If the filmmaker is to communicate this feeling concern, then, Worth continued, the "sender must develop a Story Organism - an organic unit whose basic function is to provide a vehicle that will carry or embody the Feeling Concern" (1966:327). In practice, the story organism may be a story in the usual sense of the word, even a shooting script, but Worth was dealing more with the "organization into a system of those beliefs and feelings that a person accepts as true and related to his Feeling Concern" (ibid.:328).

The final stage in the encoding process occurs when, "after recognizing the feeling concern and finding the story organism, .... the communicator [begins] to collect the external specific Image Events which, when sequenced, will become the visible film communication" (1968:4).

\section{Meaning as Mirror Image}

Worth then proceeds to define the receiving process "as a kind of mirror image of the sending process" (1966:328). Because I feel that this position contains a fundamental error (and one which Worth later recognized), I will quote it in full:

The viewer first sees the Image Event-the sequence of signals that we call a film. Most often he knows nothing of what went on before. He doesn't know the film-maker and his personality, and he usually doesn't know what the film is about, or is meant to communicate. Should our viewer choose to treat these signals as a message, he will first infer the Story Organism from the sequenced Image Events. He will become aware of the belief system of the film-maker from the images he sees on the screen.

From this awareness he will, if the communication "works," be able to infer-to invoke in himself-the Feeling Concern.

As you can see from this suggested view of the total process, the meaning of the film for the viewer is closely related to the Feeling Concern of the film-maker. The single Image Events of the film are the signals, these specifically sequenced Image Events are what we treat as messages, and our inference about the Feeling Concern of the maker is what we call the meaning of the film. [1966:328]

This view is explicitly tied by Worth to a psychological model of communication in art enunciated by Ernest Kris in his Psychoanalytic Explorations in Art (1952). Worth quotes Kris's statement that communication "lies not so much in the prior intent of the artist as in the consequent recreation by the audience of his work of art. What is required for communication therefore is similarity between the audience process and that of the artist."

The primary problem with this argument is that it does not, in fact, represent the experiential realities of film communication. ${ }^{3}$ Simply put, it is unreasonable to ever expect the process of viewing a film to mirror the process of making that film. Given Worth's own model of the filmmaking process, it should be clear that the maker interacts with the film in the process of creation in a way which can never be repeated by himself or by anyone else. The very acts of filmmaking are different in time, space, and pace from any act of viewing. Moreover, the model implies a static, unchanging feeling concern which leads to a fixed story organism, which in turn is represented by a sequence of image events. In reality, of course, the process of filmmaking - as Worth's own descriptions show-often involves changes and modifications in what one wishes to say and how one tries to say it. 
The filmmaker's experience is one of choosing among alternatives, attempting to realize intentions, and assessing achievements as a means of confirming or altering those intentions. The viewer confronts only the arranged, final set of images, and can only deal with them in terms of conventional and specific expectations, and in light of assessments of the filmmaker's control and skill in choosing, sequencing, and implying meanings. This is hardly the same thing as "[reversing] the process by which the encoder made the film" (1969:290).

But if this position is so patently untenable, why did Worth hold to it for several years and repeat it in a series of papers? I think there may be several reasons for this. First, I believe that Worth was heavily influenced by his experiences in teaching students in his Documentary Film Workshop. His method of teaching concentrated on forcing the students to clearly articulate their intentions and their decisions in selecting and arranging images in order to convey ideas and feelings. The model of a feeling concern that leads to a story organism which is embodied in a sequence of image events may not capture the experience of all filmmakers, but it does characterize the method used in Worth's workshop.

Second, the influence of the student workshop experience may have contributed another flaw of the mirrorimage model: the implication that films are typically made by individual filmmaker-communicators. This "mistake" is all the more odd given Worth's years of experience as a professional filmmaker. There is no doubt that he was aware that film is among the most collective of media and that most films could in no way be described as the embodiments of any one author's feeling concern. Worth was certainly not a naive auteur theorist; rather, I think we can see here, again, the influence of the psychologically based, individually oriented communications theory Worth was using at that time.

In his 1969 paper Worth had already begun to retreat from his claim of isomorphism between the receiver's and the sender's experience of a film. In this paper he gives several examples of possible viewer interpretations of a film (Red Desert by Antonioni) and concludes:

\section{Most film communication is not. . .that perfect corre- spondence between the Feeling Concern, the Story Organism and the Image Events they dictate, and their reconstruction by the viewer. Most film situations, depending as they must on the maker and his context (both social and psychological), the viewer and his, and the film itself, are imperfect com- municative situations. [1969:295]}

Note, however, that perfect communication is still defined as the achievement of isomorphic correspondence; context and other factors are still viewed as "imperfections" which muddy the communicative stream.

\section{Film as the Language of Visual Communication}

Despite their unfortunate devotion to the mirror-image model, these early papers were valuable for an understanding of film as communication. By using an approach that drew upon linguistics, communications theory, and psychology, Worth was explicitly differentiating himself from the evaluative concerns of film theorists who approached film primarily as an art form. The title of his 1966 paper, "Film as a Non-Art," was meant to assert provocatively this emphasis on looking "at film as a medium of communication, rather than as an art or an art form" (1966:322). He was determined that we understand the "difference between evaluation and meaning" (ibid.:324):

\begin{abstract}
My concern is not whether film is art or not, but whether the process by which we get meaning from film can be understood and clarified. . . . While all art might be said to communicate, all communication is certainly not art. [ibid.]
\end{abstract}

Having elaborated a model of the film communication process, he saw as the next step the analysis of the mediating agent- the film itself.

The study of the Image Event. . .-its properties, units, elements and system of organization and structure that enable us to infer meaning from a film - should be the subject of our inquiry, and of our professional concern. [ibid.]

In pursuit of this inquiry Worth followed the analytic paths laid down by linguists in describing and analyzing the structure and functionings of lexical communication. He adopted, in fact, the heuristic strategy "that film can be studied as if it were the 'language' of visual communication, and as if it were possible to determine its elements and to understand the logic of its structure" (ibid.:331). Worth called this visual analogue to linguistics vidistics, and proceeded to elaborate a model of filmic elements and principles based on those of structural linguistics.

\footnotetext{
Vidistics in this early stage is concerned, first, with the determination and description of those visual elements relevant to the process of communication. Second, it is concerned with the determination of the rules, laws and logic of visual relationship that help a viewer to infer meaning from an Image Event, and the interaction of Image Events in sequence. Film as if it were language, as studied vidistically, is thus thought of as the study of specified elements, elements in sequence, operations on these elements, and cognitive representations of them that act as a mediating agent in a communication process between human beings - between a filmmaker and a viewer-between a creator and a re-creator. [ibid.]
} 
Worth presented his solution to the first of these questions - the identification of the basic filmic unit, or visual element-through an account of the development of the film medium and of the theories that accompanied its growth. This account, given first in his 1968 paper, "Cognitive Aspects of Sequence in Visual Communication," was elaborated in the 1969 paper "The Development of a Semiotic of Film." After presenting various theorists' positions, Worth casts his vote with Eisenstein, who isolated the "shot" as the basic element-"the smallest unit of film that a filmmaker uses" (1969:297). This seemed "the most reasonable" choice, "not only because it is the way most filmmakers construct films, but because it is also possible to describe it fairly precisely and to manipulate it in a great variety of controlled ways" (1969:299).

Moreover, the Navajo filmmakers "who were taught only the technology of filmmaking without any rules for combining units seemed 'intuitively' to discover the shot as the basic sign for the construction of their films" (ibid.). However, as Worth himself noted in his historical account, the first filmmakers saw the "dramatic scene" as the basic film unit. This was essentially a theatrical concept: "the first filmmakers pointed the camera at some unit of action and recorded it in its entirety" (1968:9). It look several years before Porter, in 1902, "discovered" that "isolated bits of behavior could be photographed and glued together to make a scene" (ibid.:10). In retrospect, we might wonder how naive the Navajo actually were (most had seen at least some commercial films), or whether Worth had been able to limit his instruction, as intended, to "the technology of filmmaking without any rules for combining units."

Worth used the term videme for Eisenstein's basic unit of film communication, previously called an Image Event, "that is accepted by viewers as something that represents the world" (1968:13). However, Worth then argued that a finer distinction was required "if we are to attempt further scientific analysis. . . The shot is actually a generic term for two kinds of shots: the 'camera shot' and the 'editing shot' " (1969:299). The camera shot, which Worth called the cademe, is "that unit of film which results from the continuous action of the movie camera . . from the moment we press the start button to when we release it" (ibid.). The editing shot, called the edeme, is "formed from the cademe by actually cutting the cademe apart and removing those segments one does not wish to use" (1968:14). The process of filmmaking, then, involves the shooting of cademes and their transformation (in whole or part) into edemes. It is then possible to sequence these resultant edemes in ways that are determined by the individual filmmaker, his communication needs, his particular culture, and his knowledge of the "language."

The edeme thus becomes the hypothesized basic element and building block of the language, upon which all language operations are performed, and a basic image event from which all meaning is inferred (1968:14). Much of the balance of the 1968 paper was devoted to a discussion of parameters along which this basic element can vary. This discussion has much in common with the work of other writers on film (e.g., Spottiswoode 1935) who used the "film language" concept. However, Worth felt that "none of these authors developed a theory of grammar embodying 'linguistic' elements or rule-like organization capable of syntactic structures" (1968:12).

In Worth's linguistic analogy, the parameters of motion, space, and internal time are thought of as semantic elements. Sequence, however, including the manipulation of apparent time, belongs to a discussion of the syntactic aspects of the film "language" because it deals with more than one edeme at a time. "Sequencing edemes can be thought of as applying syntactic operations to edemes. This does not in itself imply a code, a set of rules, or a grammar-but it does make it possible to test visual communication phenomena along these lines" (1968:17f). Sequence becomes the fulcrum upon which Worth supported his analysis of filmic communication:

Sequence is a strategy employed by man to give meaning to the relationship of sets of information, and is different from series and pattern. As I will use the word here, sequence is a deliberately employed series used for the purpose of giving meaning rather than order to more than one image event and having the property of conveying meaning through the sequence itself as well as through the elements in the sequence. . . . Man imposes a sequence upon a set of images to imply meaning. [1968:18]

However, at this stage, Worth was still preoccupied with the quest for a universal vidistic syntax analogous to those identified by linguists and psycholinguists in the analysis of lexical communication. Following Chomsky (1957), he saw the goal of vidistics as the development of a grammar of film syntax, "whose rules we can describe in such a way that we can distinguish between what is a grammatical sequence and what is an ungrammatical sequence" (1966:334). Unfortunately for this enterprise, Worth admitted that he found "it almost impossible at this point to construct a sequence of shots that an audience will say is ungrammatical" (ibid.). Not willing to discard the concept of grammaticality in film, Worth hoped to utilize the notion of a semantic space having dimensions of meaning such as that developed by Charles Osgood, to arrive at "a grammar of probability, a system of possible, of more or less meaningful, sequences based on a concept of dimensions of syntax" (ibid.).

This prospect was explored in a series of studies Worth conducted along with Shel Feldman, a psychologist then at the Annenberg School. Some of this work was sketched in his 1968 paper, and further publications were promised, but events led him to other approaches and this line of investigation was dropped. 


\section{The Semiotic Model}

Two factors played a role in shifting Worth away from the attempt to formulate a psychological and linguistic model of film communication. First, the Navajo project, which might have served to intensify his search for a universal "psycho-logic" of visual syntax "determined by cognitive processes that all human beings share"

(1966:339), demonstrated instead that members of a culture developed film "syntax rules" which could be related to their lexical syntax and to their patterns of story-telling and their systems of value and belief.

Second, as he read more widely in linguistics and, increasingly, in the literature of semiotics-de Saussure, Pierce, and Morris-Worth found his central concern shifting to the role of social and cultural influences and away from the cognitive and psycholinguistic models he had earlier employed. ${ }^{5}$ Rather than a grammar of film as the language of visual communication, he now looked to the broader scope of semiotics for an understanding of the rules by which we make inferences from sequences of signs.

\begin{abstract}
.the development of a semiotic of film depends not on answering linguistic questions of grammar, but on a determination of the capabilities of human beings to make inferences from the edemes presented in certain specified ways.

[1969:317]
\end{abstract}

This shift permitted Worth to place the linguistic model in a perspective which had previously eluded not only him but many other film scholars. As he noted, "most theoreticians from Eisenstein to Bazin have at one time or another used phrases such as 'the language of film', 'film grammar', and 'the syntax of film' " (1969:302). More insidiously, these metaphoric uses often served more as a hindrance than an aid to the understanding of film communication. Film was all too often stretched on a Procrustean bed of linguistic models and its contours destroyed in the attempt to fit it to an uncongenial frame. Worth came to the realization that tremendous care must be taken if one is to use "that most scientific of sign disciplines" for the study of film. He returned to his initial conception of the linguistic approach as a heuristic strategy with a far more modest estimate of its utility. The strategy had, however, led him to a better understanding of how film might be scientifically analyzed.

I am suggesting, then, that linguistics offers us some fruitful jumping-off places for the development of a semiotic of film, but not a ready-made body of applicable theory leading to viable research in film. If we accept Chomsky's definition of language we must be forced to conclude that film is not a language, does not have native speakers, and does not have units to which the same taxonomy of common significance can be applied as it can to verbal language. At this point our aim should not be to change the definition of language so as to include the possible rules of film, although this may well be a result of further research in film, but rather to develop a methodology and a body of theory that will enable us to say with some certainty just how it is, and with what rules, that we make implications using film signs with some hope of similar inferences. [1969:318f]

In most of his work after 1969 Worth followed this prescription, but his focus shifted from film in particular to the larger class of visual images in general and, although the two sides of the communications process were always taken into account, increasingly his primary objective was to understand better how meaning is interpreted by viewers rather than how it is articulated by the imagemaker. Before discussing these investigations, however, I want to turn to some important papers in which Worth applied the lessons of his theoretical research to the practice of those engaged in the use of visual media in anthropology and education.

\section{The Politics of Anthropology}

The most immediate application of Worth's emerging semiotic approach to film communication was in the field of anthropology. I have already mentioned his involvement with the sub-discipline of visual anthropology. With the completion of the Navajo project Worth found himself near the center of a growing "invisible college" of anthropologists interested in going beyond the limited uses of visual media characteristic of most work in the field. Visual anthropology, despite the important early contributions of Bateson and Mead, had come, for the most part, to mean the taking of photographic or film records in the field, and the use of these materials as illustrations to accompany verbal accounts or as "evidence" uncritically accepted as objective records of objects and events.

In a paper presented to the American Anthropological Association in 1968, entitled "Why Anthropology Needs the Filmmaker," Worth took strong exception to these assumptions and to the biases and limitations they entailed. In the first place, he maintained that we could not simply accept photographic or film images as "evidence" because they always reflect human decisions (conscious and unconscious) and technological constraints.

Further, he argued that by defining film exclusivelyand naively - as a record about culture, anthropologists tended to ignore the study of film as a record of culture, "reflecting the value systems, coding patterns and cognitive processes of the maker" (1972a). Here, in addition to the obvious echoes of the Navajo project, Worth is explicitly drawing upon Hymes's concept of the "ethnography of communication" in which one is interested in what things are said (or not said), why, to whom, and in what form. 
As a corollary of this position, Worth was led to the view that any film can be used for ethnographic analyses - of the culture of the film's subjects or of the filmmaker, or both; consequently,

[t]here can therefore be no way of describing a class of films as "ethnographic" by describing a film in and of itself. One can only describe this class of films by describing how they are used, and assigning the term "ethnographic" to one class of descriptions. [1972a]

Worth's argument was controversial, for it implicitly denied the inherent ethnographic validity of much "anthropological film"-it was not ethnographic just because an anthropologist made it. In fact, he went much further and attacked the "visual anthropologists" for their lack of sophistication in the use of film, a condition which he attributed in part to their naive view of film as "objective record":

The only group of professionals involved in the making and use of anthropological films who have no training AT ALL in the making, analysis, or use of film are anthropologists. One can count on the anthropologists who are trained to study films, not as a record of some datum of culture, but as a datum of culture in its own right. [1972a:359]

By the late 1960s Worth was actively engaged in efforts to change this state of affairs. He was involved with the American Anthropological Association's (AAA) Program in Ethnographic Film (PIEF) and in 1970, in collaboration with Margaret Mead and others, he helped found the Anthropological Film Research Institute at the Smithsonian Institution. In the summer of 1972 he organized and taught, along with Jay Ruby, Carroll Williams, and Karl Heider, a summer institute in visual anthropology funded by the National Science Foundation. That fall, at the annual meeting of the AAA, Worth was instrumental in the transformation of PIEF into the Society for the Anthropology of Visual Communication. He served a term as president of the society and was the founding editor of its journal, Studies in the Anthropology of Visual Communication. ${ }^{6}$ The society and the journal provided a continuing form and context for Worth and others to advocate and demonstrate the rich potential of the approach they represented.

\section{The Ethics of Anthropology}

The issues Worth was raising in the late 1960s and early 1970 s did not exist in a vacuum; in a real sense they were in the air. Anthropologists along with the rest of academia were facing political and social realities which cast into question many of the untested assumptions of their discipline. In 1972 a volume of essays appeared under the title Reinventing Anthropology, edited by Dell Hymes, in which sixteen authors discussed the field as a product of "a certain period in the discovery, then domination, of the rest of the world by European and North American societies" (Hymes et al. 1972:5). The essays in the book addressed many assumptions, biases, and limitations of anthropological theory and practice, exposing flaws and ethical problems and questioning whether it was possible to "reinvent" a more responsible and self-conscious discipline.

Worth contributed a chapter to this book in which he explicated many of his concerns about the way anthropologists have used and misused, understood and misunderstood the visual media in studying and reporting about various groups around the world. He identified a series of intellectual and ethical problems that have resulted from the development and diffusion of visual communication technologies.

For the field of anthropology Worth argued that "an ethnography of communication developed on the basis of verbal language alone cannot cope with man in an age of visual communication" (1972b:349). He maintained, as I have already noted, that the naive belief in film as objective record must give way to a more sophisticated understanding and use of visual media as research tools and of visual images as research data.

Worth also criticized the inertia of academic disciplines which leads us to "continue examining and thinking about only inherited problems, rather than those problems and modes our children, our students, and even ourselves pay most attention to" (ibid.:350). We cannot ignore the growing centrality of the visual media in all cultures, not only in Western industrial society. He spelled out in this paper some of the ways in which social scientists can become more sensitive students of contemporary, "visual culture."

The ethical problems he articulated are more difficult to resolve. When Worth first began to develop the biodocumentary method, he saw it as a way to learn "how others see their world," to "make it easier for them to talk to us" (1965:19). The Navajo project was an expression of his belief in the potential of film to reverse the one-way flow of most anthropological communication. But, in this paper, he reveals a considerably less sanguine view of the role of visual media in the lives of "others" in the modern world.

The Navajo project had as one of its aims the study of the "guided" introduction of a communications technology into a new cultural context. In the 1972 paper Worth is 
all too aware of the realities of technological diffusion in the modern world. For most cultures and societies the question is not whether they will encounter and come to live with these new visual media, but when and how.

In teaching people to read, we implicitly teach them what to read. . . . The use of a mode of communication is not easily separable from the specific codes and rules about the content of that mode. [1972b:351]

One central problem, therefore, is that our technologies may carry with them "our conceptions, our codes, our mythic and narrative forms" (ibid.:353) unless we also make clear to other cultures that these new media "need not be used only in the ways of the. . societies that introduce them" (ibid.).

Another ethical question raised in this paper focused on the importance of control over information as an instrument of power. Worth noted that "anthropologists are notorious for studying everyone but themselves" (ibid.:355). Is it appropriate for us to encourage others to reveal themselves when we do not? As visual technologies spread to groups in our society and to other cultures unused to manipulating these media,

what is our responsibility to help them to understand a world in which their every act of living can be televised and viewed by a watching world? . . . Should we teach them not only to make their own films but to censor ours as well? The problem as I see it is: What reasons do we have not to insist that others have the right to control how we show them to the world? [ibid::355-358]

\section{Film in Education}

Although I have concentrated on Worth's extensive involvement with anthropology, some of his earliest academic endeavors were in the field of education. His interest in this area was revived in 1971 when he was invited to contribute to a Yearbook which was to focus on communication and education. He agreed to write a paper on the use of film in education and he took the opportunity to draw together and to clarify several strands in his previous and current thinking.

Worth began by examining three perspectives which he saw as exercising major-and pernicious-influence on "the educational and film communities but with very little research evidence in their support" (1974a:273). First, and most intensely, he takes issue with Rudolf Arnheim's position, which he characterized as "visual primacy." Worth argued that Arnheim's theory of "visual thinking" carries to an unreasonable extreme the "reasonable assertion that visual perception contains or is part of what we normally call 'thinking'" (ibid.).
I believe that this is a fair characterization of Arnheim's work, and Worth goes on to pinpoint some of its major flaws. Rejecting in Arnheim an extreme version of the psychological, perceptual-cognitive "bias" he himself had earlier manifested (although he never expressed such a strongly "Gestalt" position), Worth concluded that Arnheim "underestimates or denies the extent to which symbolic systems or conventions mediate our knowledge of the world" (ibid.).

The particular error Worth located in Arnheim was most clearly manifested in his denial of the crucial role of culture in determining what and how we "see":

True visual education presupposes that the world can present its inherent order to the eye and that seeing consists in understanding this order. [Arnheim 1966:148]

In contrast to this position Worth aligned himself with most contemporary thinkers in saying that

what we see and what we think about is determined at the least as much by our symbolic systems and conventions for representing that universe as by the universe itself.

[1974a:278]

Worth went on to outline the other two perspectivesthat of certain film theorists (represented by Gene Youngblood) and film educators-which he felt were as inadequate and misleading in their own areas as Arnheim was in his. What these criticisms have in common is Worth's dismay at the failure of so many researchers and educators properly to understand or utilize film as a process of communication.

In the remaining sections of the paper Worth presented his own current view of how film could be understood as communication and how knowledge of this process enables us to use film in the very process of education itself. He restates an abbreviated version of the feeling concern/story organism/image event model (these terms are not used), but with several significant modifications. In this account the complexity and non-linearity of the filmmaking process are now emphasized, moving the model away from the somewhat misleading implication that the filmmaker moves in strict, irreversible steps from feeling to story to image sequence. However, the model is still conceived in "single author" terms. This is shown explicitly when Worth describes the completion of filmmaking:

At some point he decides to "release" his film. It is now no longer a personal act but a public and social one; it is a symbolic form available for participation in a communication process. [ibid.:285] 
Worth was also ready to abandon the mirror-image model of viewer reception, if somewhat reluctantly:

When another person sees this film, he must (depending on how one talks about such acts) receive it, decode it, or recreate it. Since meaning or content does not exist within the reel of acetate, the viewer must recreate it from the forms, codes, and symbolic events in the film. ... For communication to occur, meaning must be implied by the creator and inferred by the viewer or re-creator. [ibid.]

Note that, while perfect communication is no longer defined in terms of the viewer's ability to trace the filmmaking process in reverse and reach the author's feeling concern, the terminology suggests an ambivalence that probably reflects a genuine state of intellectual transition. Worth shifts between "receive," "decode," and "re-create" to describe the viewer's role in the process of communication, still echoing the isomorphic implications of "recreation" as he had used the term in earlier papers. Yet he also makes explicit the role of "conventions through which meaning is transmitted between people by a process of implication and inference" (ibid.).

Worth was now coming to focus more and more on the process of interpretation-how meaning is created by viewers-rather than on the process of articulation by imagemakers (as in the bio-documentary and Navajo projects). In order to clarify the importance of this shift, I have to backtrack to an earlier stage in Worth's work.

\section{Ignoring Interpretation}

In one of his earliest papers Worth had introduced a discussion of audience reactions to his students' films with the comment, "Perhaps, in an attempt to understand a particular act of communication we can approach understanding by examining the reaction to the act, rather than the act itself" (1965:3). However, in most of his work over the next six years Worth focused more on the act of making than on that of interpreting meaning from images. In the study of bio-documentaries made by various groups in our society (reported in Worth and Adair 1972, Chapter 15), and in the Navajo project, it was the films and the activity of the filmmakers, not the viewers, that Worth was interested in.

In his 1966 paper, "Film as a Non-Art," Worth appeared willing to forego the investigation of the interpretive side of the communicative process:

This particular area of study - the interaction between persons and groups, and the stimuli they relate to-has been undertaken by the social and behavioral scientists. Although relevant to our interests, the specific study of the relationships between people and events cannot be the professional concern of those interested in visual communication. [1966:330]
Although I believe he was primarily distancing himself from an overly subjective approach which centers on individual viewers' reactions, Worth is clearly advocating the priority of the "study of the Image Event" itself. The extent of this "bias" is shown by the perfunctory way in which Worth and Adair assessed the reactions of other Navajo to the films made by their fellows. The account given by Worth and Adair of the films' world premiere on the reservation (attended by 60 Navajo) is the shortest chapter in their book (1972:128-131), but it is most revealing

They make clear the fact that the idea of holding the screening at all originated with the filmmakers, not the researchers. More importantly, the account reveals how unprepared they were for this crucial opportunity to investigate the interpretations and responses of the Navajo viewers. Only nine viewers were questioned, and the questions failed to explore fully their reactions.

Two of the Navajo reported that they did not understand certain of the films. These were films judged by Worth and Adair to be "somewhat outside the framework of Navajo cognition" (ibid.) either in form or subject matter. The way these viewers expressed their lack of understanding was to say that they didn't get the meaning because the films "were in English." This is a most intriguing response, considering that none of the films had any sound at all. However, Worth and Adair continue:

Since these interviews were conducted in Navajo, we didn't see the translated tapes until we left the reservation, and have not been able to question our informants further along these lines. [ibid.:131]

By the early 1970 s, in contrast, Worth was clearly insisting on the need to include the perspectives of both the interpreter and the imagemaker within the scope of investigation. In part, as I have indicated, this insistence was influenced by Hymes's advocacy of an "ethnography of communication."7 However, in order to fully describe the development of Worth's work at this time, I have to discuss my own involvement with it. 


\section{Personal Interlude}

I met Sol Worth in the spring of 1968 when I visited the Annenberg School for the first time. My decision to join the faculty of the school (as opposed to taking a job in the field-social psychology_in which I had just received a Ph.D.) was motivated in large part by Worth's presence. It was immediately clear that we shared a strikingly similar set of interests and intellectual inclinations; and it was Worth who convinced me that my interests in the study of art and culture could be pursued far more readily in a communications program, where they were seen as central, than in a psychology department where (I already knew) they would be seen as peripheral. Certainly, my experience with the psychology of art subfield had been disappointing: those who seemed to have a feeling for art used poor psychology (e.g., Arnheim), while those who were psychologically rigorous did not seem to understand art (e.g., Berlyne). The field of communications-at least as it was represented at the Annenberg Schoolappeared to offer a framework in which the varieties of symbolic behavior (especially the kinds we call art) could be studied with a sensitivity to the role of psychological, social, and cultural determinants.

From the outset Worth and I engaged in discussions and arguments which helped both of us clarify and, I hope, improve our understanding of communications phenomena. In these discussions, I made clear my belief that the interpreter's role was at the center of the communicative process. Put most simply, I argued that before one could become a "sender" one had to become a "receiver." The competence needed for articulation derived in large part from one's prior experience in interpretation. Specifically, in the realm of art I maintained that "the process of artistic creation itself presupposes and arises out of the process of appreciation" (Gross 1973:115).

This position reflected two basic considerations. The first was the simple fact of ontological sequence: we all encounter symbolic events first as consumers and only later, if at all, as producers. "Only upon the basis of the competence to appreciate meaning presented in a symbolic mode can one hope to achieve the realization of creative potential in that mode" (Gross 1974:71).

Second, I was arguing that symbolic behavior occurs in a variety of distinct modes, and that meaning can be understood or purposively communicated only within these modes. "These modes are partially but not totally susceptible to translation into other modes. Thus they are basically learned only through actions appropriate to the particular mode" (ibid.:57).
Two papers which I wrote in 1971-1972 presented the outlines of a theory of symbolic competence and aesthetic communication which incorporated this position $(1973,1974)$. These papers and the theory they presented owed much to Worth's influence. At the same time my views and emerging theoretical formulations helped shape his views on a number of isues. The paper Worth wrote on film and education reflects our discussions. By the fall of 1971 these discussions had led-via an informal research seminar we conducted - to collaborative projects carried out by several of our students, and eventually to a joint paper.

This paper, written in 1972-1973 and published in 1974 , presents the outlines of a theory of interpretation-the assignment of meaning to objects and events. Because I feel that the presentation in the paper is often unclear and overly terse, and because the model introduced in this paper figures importantly in Worth's subsequent writings, I will risk the appearance of immodesty and attempt to remedy some of the paper's deficiencies by discussing its contents in somewhat greater detail than I have devoted to the other papers.

\section{Interpretive Strategies}

The questions we focused on in our discussions and research centered around the peculiar properties of visual images. Although our paper addressed the general issue of how people assign meaning to objects and events, in retrospect it seems clear that our concerns were mostly directed towards the visual mode in general, and film or photographic images in particular. The basic question we were asking might be phrased as: what can we "know" from these images and how can we know it? We felt that the first step towards an answer was to draw two basic distinctions in describing interpretive processes.

The first distinction we made was between those objects and events which do and those which do not "evoke the use of any strategy to determine their meaning" (Worth and Gross 1974:29). Most of the objects and events we encounter are interpreted "transparently" in the sense that we "know what they mean" without any conscious awareness on our part of any interpretive activity. We generally respond to their presence (or absence) in a way which indicates (analytically) that a process of tacit interpretation has occurred: our behavior has been affected by the presence (or absence) of some object/event in some fashion. We simply haven't needed to "think about it." Such tacit interpretations range from our "unthinkingly" extending our hand to open a closed door when we leave a room, to our ability to drive a car along a familiar route while absorbed in conversation or reverie.

Worth and I used the term "non-sign events" to identify the events that we ignore or code "transparently." The 
objects and events which do evoke an interpretive process we called sign events. However, we continued, these are not predetermined or fixed classes:

It is important to note that the distinction between sign and non-sign events must not be taken as a categorical classification of persons, objects, and events. Any event, depending upon its context and the context of the observer, may be assigned sign value. By the same token, any event may be disregarded and not treated as a sign. [ibid.]

The purpose of this first distinction, therefore, was not to isolate two kinds of objects and events in the world, but two ways in which we respond to the presence or absence of objects and events. Having made this distinction we turned our attention to the ways in which sign events are interpreted. Our second discrimination was between those sign events we called natural and those we called symbolic.

Natural events, as we used the term, are those which we interpret in terms of our knowledge (or belief) about the conditions that determine their existence. The meaning of these events for us, in fact, can be said to derive precisely from those existential conditions. They are informative about the stable and/or transient conditions of the physical, biological, and/or social forces that determined their occurence (or non-occurrence) and configuration. The important point here is that, while we assign meanings to such events on the basis of knowledge (or belief) about the forces that caused them to exist, we do not see them as having been caused (to any important degree) in order to convey these meanings to us. Therefore, while they inform us about those factors which we assume (or know) to have caused their occurrence, we do not sense an authorial intent behind them.

Natural events may be produced by either human or non-human agency. "However, the signness of a natural event exists only and solely because, within some context, human beings treat the event as a sign" (ibid.). To give a simple example, if I observe a tree bending in the wind, my knowledge of meteorology may lead me to interpret it as a sign of a coming storm. My interpretation is based upon my knowledge of the forces that caused the event to occur.

Similarly, I may decide that a person I observe on the street is a former member of the armed forces because I notice that he has a crew cut, very erect posture, and walks with a slight limp. In this case I would be basing my interpretation upon stereotypic knowledge of the factors that would result in this configuration of characteristics. Needless to say, I could be mistaken. The point, of course, is that I would be treating the signs I attended to as informative about stable and/or transient characteristics of the persons I observe and/or their interactions with the situations in which I observe them.
In contrast, symbolic events are events we assume to have been intended to communicate something to us . Further, we assume that these events are articulated by their "author" in accord with a shared system of rules of implication and inference. That is, they are determined not by physical or psychological "laws" but by semiotic conventions. To assess a sign event as symbolic, then, is to see it as a "message" intended by its "author" to imply meaning(s) which can be inferred by those who share the appropriate code.

If I were to observe, for example, that the man I saw on the street, in addition to having a crew cut, erect posture, and a slight limp, wore a lapel pin which read "V.F.W.", I could then draw the inference that he was, in fact, a veteran and, moreover, that he was communicating rather than merely revealing this fact (I leave aside the obvious possibility of deception, both communicative and "existential").

Worth and I called the interpretation of natural events "attribution" and the interpretation of symbolic events "inference." The former term was adapted from the area of attribution theory within social psychology. Originally developed by Fritz Heider in the 1940s, and revived in the late 1960s by Harold Kelley (1967) and others, attribution theory focuses on the process by which individuals interpret events "as being caused by particular parts of the environment" (Heider 1958:297). However, our use of the term attribution as a label for the interpretation of natural events is narrower than that used in social psychology, because we limited it to those interpretations which do not assume authorial intention.

On the basis of these distinctions we proposed a definition of communication which, in effect, is limited to the articulation and interpretation of symbolic events:

Communication shall therefore be defined as a social process, within a context, in which signs are produced and transmitted, perceived, and treated as messages from which meaning can be inferred. [Worth and Gross 1974:30]

Although I have presented these distinctions and definitions in a rather general fashion, we had in mind a particular set of events and situations - those not obviously and easily defined as natural or as symbolic. We were interested, that is, in what we termed ambiguous meaning situations.

Most of the time there is little difficulty in deciding whether an object or event we notice is natural or symbolic. Most people who might observe the wind bending a tree outside their window and decide to take an umbrella when they go out would not think the wind was "telling" them that it might rain. Similarly, if we meet someone who speaks English with a distinct accent we may attribute foreign origin to the person but we are unlikely to decide that the accent was intended to communicate the speaker's origin (however, if we find out that 
the speaker left his or her native country many years before at an early age, we may wonder about that assessment).

When we encounter a symbolic event, on the other hand, we are likely to see it as intentionally communicative. We usually have little difficulty recognizing these as communications addressed to us as individuals or as members of a group, provided we know the code. And we usually have little difficulty interpreting them, again providing we know the code. Traffic lights are rarely mistaken for Christmas decorations.

One further clarification needs to be made. We were focusing on the perspective of the person who observes the sign event and interprets it. A sign event is symbolic (i.e., communicative) only if it is taken as having been formed (to an important degree) with the intent of telling something to the observer. That is, if the observer is watching two people converse and knows that they are unaware they are being observed, their conversation, while it is a communicative event for them, is a natural event for the observer. It was not intended to tell the observer anything, and so it can only be seen as informative about the speakers' stable and/or transient characteristics as revealed in that situation. Of course, certain aspects of the observed event, such as the participants' clothing or hairstyles, might be assessed as being "messages" addressed not just to the other participant but to the "public" at large; these aspects might then be assessed as symbolic vis-à-vis our observer.

\section{Life vs. Art}

With all these concepts in mind, we turn to events we encounter not through direct observation but through photographs or film. Here we find the situation to be more complex and more interesting. The point of the exercise, really, was to develop a way of dealing with the interpretation of those mediated events (although mediation can occur through words and paintings, etc., as well, photographic mediation is the most ambiguous and therefore the most interesting case).

In our paper we make the suggestion (supported by empirical studies) that there is a learning process by which we come to know how to interpret mediated symbolic events such as films. At the simplest level we merely recognize the existence of persons, objects, and events in the film and make attributions about them based on our stereotypic knowledge of such things in real life. With somewhat more sophistication we can see relationships between objects and events that are contiguous in time and/or space - they go together. The cru- cial step, then, is to see this contiguity as the result of an intention to tell us something - to see it as a sequence or pattern which is ordered

for the purpose of implying meaning rather than contiguity to more than one sign event and having the property of conveying meaning through the order itself as well as through elements in that order. [ibid.:32]

The final stage in this hierarchical process is when we recognize the structure of a sign event, an awareness of the relations between non-contiguous elements and their implicative-inferential possibilities: the beginning and end of a story, variations on a theme, prosodic patterns, etc.

When we look at a scene recorded on film we need to decide whether the event was (among other possibilities): (1) "captured candidly" as it unfolded naturally in front of the camera, with the participants seeming not to know they were being filmed; (2) photographed unobtrusively so that, while the participants knew about it, it was done in such a way that they "almost forgot" they were being filmed; or (3) scripted, staged, and directed by an "author" working with actors.

If we settle on the first alternative, we are likely to feel justified in making attributions about the persons in the film (their characteristics, their feelings, their relationships, etc.). If we choose the second alternative we may feel somewhat less confident in making such attributions, as we will feel that the behavior we observe was somewhat constrained by their knowledge that they were being filmed. That is, their behavior may be less informative because we know it is also "messageful."

If we take the third alternative we are unlikely to make attributions of the former sort; here we will interpret the scene in light of our knowledge of dramatic conventions. These conventions may be nearly the same as the attributional stereotypes we use in the first two instances (consequently they might lead us to similar interpretations), and this is not surprising: naturalistic conventions in drama aim precisely at evoking attributional knowledge in order to convey "lifelikeness" to characters and situations. However, they need not be the same. We may "know" that the cowboy in the black hat is the bad guy without also believing that anyone we see in real life wearing a black hat is a criminal.

The point is that, although events encountered in "life" and in "art" may look the same, we make different assumptions about the factors that determine their occurrence and configuration. Because the conclusions reached may be the same, in order to decide whether an interpretation is attributional (the observer is assessing the event as "life" - a natural event) or inferential (the observer is assessing the event as "art"-a symbolic event), we need to know the grounds on which it would be 
justified. If asked how we know something we have concluded about an event we have observed, we might say it is because of what we know about the way such things happen (attributional interpretation); or we might say we know it because we are assuming the event was made to happen that way in order to tell us something (communicational inference).

We hoped that this model would clarify some issues Worth had addressed in earlier papers. Most immediately, it allowed us to say that the tendency to see films as objective records of events rather than as a filmmaker's statement about events derived from a confusion of interpretive strategies. The naivete Worth had attacked in many anthropologists and others who were filmically unsophisticated took the form of assuming filmed events could uncritically be interpreted as natural. What such viewers failed to understand was that all mediated events are to some degree symbolic. There are always decisions made by the mediating agent-what to shoot (and consequently, what not to shoot) and how; and having shot, how to edit the footage (one rarely sees raw footage); and finally when, where, and how to exhibit the finished film.

A sophisticated viewer will recognize that the persons, objects, and events in a film are there at least in part because the filmmaker included them intentionally; that the sequence of events in the film has been ordered by the filmmaker's intention to say something by putting them in that order (which may not be the order in which they actually occurred); and that the overall structure of the film reflects the filmmaker's intention and ability to use implicational conventions in order to communicate to viewers who are competent to draw the appropriate inferences.

From this perspective it should be clear why Arnheim's statement that "the world can present its inherent order to the eye and that seeing consists in understanding this order" so infuriated Worth. He saw this view as contributing to the kind of approach to film represented by Youngblood's advocacy of a cinema which was "entirely personal . . . rests on no identifiable plot and is not probable. The viewer is forced to create along with the film" (Youngblood 1970:64). Worth's response to this was fierce:

Tyros in the arts always forget that creation and originality cannot even be recognized (or perceived) except within a context of convention and rule-like behavior-especially in the arts. It is not within the context of an ordered universe that art exists, but rather within the context of man's conventions for ordering that universe. [1974:282]

\section{Cracking the Code}

In the period following the initial development of our theory of interpretation Worth devoted much of his attention to the elaboration and extension of this approach to understanding how people derive meanings from visual images. He was interested in exploring both the properties which were unique to visual communication and those which could be generalized to other symbolic modes. One of his first efforts in the latter direction came in response to a request that he prepare a commentary on a special issue of New Literary History devoted to metaphor.

Worth began his paper with the observation that "every author [in the issue] 'assumes' that metaphor is a verbal event - a verbal 'thing' of some sort" (1974b:195). He then posed the question of whether-and how - the concept of metaphor could be applied to events in other modes. The answer he gave was that "metaphor is a structure composed of elements in any mode. . . related in certain ways" (ibid.:196). The rest of the paper was largely directed towards an analysis of the metaphoric possibilities of visual images and the argument that "visual structures can clarify a general and abstract notion of metaphor" (ibid.:197).

Worth described several examples of filmic metaphors and said that the problems they raise are those of "syntactic forms for nonverbal matters for which we have very little social agreement" (ibid.:199). How do we know what such metaphors mean?

When Eisenstein used a sequence in his film Strike in which a close-up of a factory foreman (who has informed the cossacks about a coming strike) is followed by a close-up of a jackal, audiences interpret this as "akin to the verbal notion of 'the informer is a jackal'" (ibid.:198). Or, to repeat an earlier example, we "know" that the cowboy in the black hat is the bad guy. Worth's point here was that the understanding of metaphor depends upon our ability to apply the correct interpretive strategy to infer the implied meaning:

\footnotetext{
Metaphor is a communicational code depending upon the recognition of structure and the assumption of intention on the part of the "articulator" . . . of the form we are to treat as metaphor. [ibid.:200]
}

For example, it is our recognition of metaphoric intention that tells us Eisenstein has sequenced his shots in order to imply that foreman $=j$ ackal, and that we should not read these as merely contiguous events. In this case, the brief introduction of the jackal shot as a "break" in the plot signals us that it is a metaphoric comment rather than a narrative development. "The important point is that every culture provides its 'native speakers' in any mode with a code for interpretation" (ibid.:202). 
Worth devoted the second half of the paper to an analysis of caricature as visual metaphor. Using Sparshott's conception (in the collection he was discussing) that metaphor is "talking about something as it is not," Worth suggests that

metaphor might most fruitfully be understood in comparison with theories and concepts of caricature rather than with theories of representation. [ibid.:204]

Noting that verbal metaphors are statements which are neither literally true nor false, Worth says that a caricature is

a structure that reveals a set of meanings intended to communicate a certain set of relationships within some understood or understandable context and bounds. . . . A caricature is . . . a structure that relates several elements on one level (in shorthand-that of "reality") with elements on another level (the symbolic). It puts things together both as they are and as they are not, and the point of caricature, like that of metaphor, is that neither is only a "portrait." [ibid.]

Metaphor, in Worth's analysis, thus becomes a central component of the structural code we learn "for the intentional creation of meaning within specific contexts" (ibid.:209). It is a particularly rich syntactical device for implying and inferring meanings in each mode of symbolic experience.

Knowing about metaphor means knowing how to organize the universe within our minds, knowing systems of myth, of grammar, of behavior, value and art as they are defined by our group now, and have been in the past. [ibid.:208]

\section{What Pictures Can Say}

The larger questions raised by Worth's analysis of metaphor were addressed in his next paper, in which he set out "to begin an exploration into how, and what kinds of things pictures mean" and also to explore "how the way that pictures mean differs from the way such things as 'words' or 'languages' mean" (1975:85). ${ }^{8}$

The title of the paper, "Pictures Can't Say Ain't," signals one of its main arguments, namely that among things pictures cannot imply are negative statements. But before getting to that point, Worth began by discussing the general status of pictures as symbolic events.

Using the model of symbolic vs. natural events first presented in our joint paper, Worth argued that a picture is never a natural event, but always a "created social artifact." He then recounts the notions of attributional interpretation as contrasted with communication inference, making the point that an appropriate interpretation of any picture always assumes that it was structured intentionally for the purpose of implying meaning. Worth invokes Grice's classic analysis of intention and meaning, quoting Grice's view that not merely must a symbolic event have been articulated "with the intention of inducing a certain belief but also the utterer must have intended an audience to recognize the intention behind the utterance" (Grice 1957:382).

The next point Worth emphasizes is that we must learn to interpret pictures by learning the system of conventions - the code - used by their makers to imply meanings. Pictures cannot be taken as merely "corresponding" to reality, and therefore we do not merely "recognize" what they mean; we infer meanings on the basis of learned conventions.

Worth here is arguing against two groups who have denied that pictures carry intentional meaning: certain logical positivists and linguists who believe that only "the linguistic mode is capable of meaning" (Worth 1975:93), and others, including some artists, who feel that pictures can mean anything anyone sees in them. "No artistic implication should. . . become a grab bag for everyone to reach into and pull out what he himself has put in" (ibid.:97).

It we take art seriously as communication, we must acknowledge the separate roles and responsibilities of the artist and the audience. Each performs a distinct and complementary task in the communicative process. The audience doesn't make the work, but interprets it:

the reader ... does not write any part of the poem, any more than the viewer paints the picture or makes the film. The reader (viewer), if he can participate in a communications event, recognizes the work's structure, assumes an intention to mean on the part of the creator, and proceeds to his extremely complex job of making inferences from the implications he can recognize. [ibid.] 
Turning next to the question of what "pictures cannot do that words can do," Worth answers that "pictures cannot deal with what is not"; they can't say ain't. After disposing of several trivial examples of what might be seen as pictorial negation, calling these "linguistic uses of visual form which become sign events in a special language" (e.g., "no smoking" images), he discusses the general concept of what pictorial images affirm or deny.

Although much of "what is pictured is often valued for what it negates by leaving out," pictures cannot specify, out of all the things that are not shown, which the painter means to say are not the case. "All that pictures can show is what is -on the picture surface" (ibid.:98).

On the other hand, pictures should also not be taken as necessarily affirming the existence of what they do show. Worth draws a connection between the fact that pictures seem to show us things - particularly photographs, which we tend to believe are the product of a machine that "tells it like it is"-and our tendency to see "false" pictures not as negations but as false affirmations.

Pictures in and of themselves are not propositions that make true or false statements; that we can make truth tables about, or that we can paraphrase in the same medium. Pictures, it must be remembered, are not representations or correspondences, with or of, reality. Rather, they constitute a "reality" of their own. [ibid.:102]

But, if this is the case, how do we make sense of pictures? What do they tell us and how? Worth gives two answers: first, pictures imply - and we infer-an existential awareness of particular persons, objects, and events that are ordered and structured so as to imply meanings by the use of specific conventions; second, "what Larry Gross [1973] has termed the communication of competence." Pictures communicate the skill and control with which their structures have been manipulated according to a variety of rules, conventions, and contexts.

Pushing the argument further, Worth reiterates the point that "matching to the real world is insufficient to explain how pictures mean," and goes on to say that

correspondence, if it makes any sense as a concept, is not correspondence to "reality" but rather correspondence to conventions, rules, forms and structures for structuring the world around us. What we use as a standard for correspondence is our knowledge of how people make picturespictorial structures - how they made them in the past, how they make them now, and how they will make them for various purposes in various contexts. [ibid::104]

Worth's answer, then, to the question he had posed at the beginning of the paper is that pictures communicate "the way picture makers structure their dialogue with the world."

\section{Toward an Ethnographic Semiotic}

Worth's theoretical investigations did not draw him away from his concern with the development of a discipline which studies visual communications in a fashion compatible with that theory. In 1976 he delivered a paper at a symposium honoring Margaret Mead on her 75th birthday (1980). That paper adressed the need for scholars to understand properly the uses and the limitations of visual communications.

He distinguished between the use of visual images and media as research tools and as research material. In the case of the former he used Margaret Mead's work with Gregory Bateson as an example of how pictures can be used by a researcher to illustrate patterns of culture. The point he felt needed to be emphasized once again - it is a point we all forget too easily - is that "the photo is not the pattern" but something we use as evidence to illustrate pattern.

Taking photographs, or looking or taking notes are tools for articulating and stating patterns we, as anthropologists, wish to show to others. [ibid.:17]

And there is an important corollary: the value of the photograph lies in the analysis. The researcher-photographer who understands what patterns he or she wishes to present will take photographs which will be capable of showing these patterns to others. Success is not a matter of luck but of training, skill, and intention. Bateson's and Mead's photographs are valuable because of their knowledge of what they were photographing and why they were photographing.

The reason their photographs and films are records is that they were taken in ways which allowed them to be analyzed so as to illustrate patterns observed by scientists who know what they were looking for. [ibid.]

The second use of photographs and films is as objects and events which can be studied in the context of the culture within which they were used. Here the pattern is in the picture and the context(s) of its making. These images are analyzed as parts of culture in their own right, "just as conversations, novels, plays, and other symbolic behavior have been understood to be" (ibid.).

This latter approach is one Worth was later to call ethnographic semiotics, the study of how actual people make and interpret a variety of visual images and events. These images and events range from the personal and private to the collective and public, from painting and sculpture through television, movies, and photographs (including home movies, snapshots, and photo-albums), store windows, and other forms of everyday presentation of self through visual means. 
Here one looks for patterns dealing with, for example, what can be photographed and what cannot, what content can be displayed, was actually displayed, and how that display was organized and structured. Was it arranged according to how these people tell stories? To how they speak, or to the very language and grammar that they use? [ibid.]

In the last two years of his life Worth gave considerable attention to the formulation of an empirical application of his concept of an ethnographic semiotics. He was determined to demonstrate rather than merely to advocate the feasibility and validity of his aproach to the study of visual communications. At the time of his death he was preparing two grant applications. The first was for a fellowship that would give him a year in which to write a book, Fundamentals of Visual Communication, which would present a framework through which the process and structure people use to make interpretations of our visual universe might be understood.

The second application was for a grant to support a project he proposed to conduct with Jay Ruby. That project, to be carried out over a period of three years, was to be a study of the visual symbolic environment of a small American community in central Pennsylvania. This was an enormously ambitious and exciting project, proposing to use as the unit of analysis not specific symbolic products but the "context-the community and the community members' interaction with visual symbolic events."

In his paper honoring Margaret Mead Worth noted, "I am aware that, even as we try to develop a history in this field, we also are in many ways that same history." Sol will remain an important part of the history of studying visual communications.

\section{Notes}

1 In the preparation of this introduction I benefited from comments and suggestions by George Custen, Paul Messaris, Jay Ruby, and Tobia L. Worth. I also drew upon Richard Chalfen's paper, "The Contributions of Sol Worth to the Anthropology of Visual Communication."

2 The choice of the Navajo in this example was not accidental. Worth had already been discussing this idea with John Adair, a longtime student of the Navajo, who later collaborated with him on the project.

3 I should mention here the fact that Worth's later repudiation of the mirror-image model was in large part the result of many discussions between the two of us during the period 1968-1972. The arguments summarized in this paragraph represent the position I maintained in opposition to the implication on Worth's part of sender-receiver "isomorphism" in the communication process.

4 I should alert the reader that later, in our joint paper, "Symbolic Strategies" (1974), this terminology was significantly altered. Needing a general term for intentionally articulated arrangements of elements, Worth and I used "order" for this purpose, using "sequence" to designate temporal orderings and "pattern" to designate spatial orderings of sign elements. In contrast to "order" we used the term "contiguity" to designate the "juxtaposition of units or events over time, space or position" (1974:32) where the perceiver does not assume that this arrangement was intended to imply meaning(s).

5 A major influence on Worth's thinking at this time was the emerging field of sociolinguistics. In particular, he was impressed with the work of Dell Hymes, who had come to the University of Pennsylvania in 1965.

6 As of the Spring 1980 issue (6:1), the name of the journal was changed to Studies in Visual Communication.

7 Richard Chalfen, who had assisted on the Navajo project, was at that time conducting dissertation research which combined the approaches of Worth and Hymes. Chalfen used the term "sociovidistics" to designate an "ethnography of film communication" (Chalfen 1974, 1977).

8 Many of these questions were also addressed in a later paper, "Man Is Not a Bird" (1978).

\section{References}

- Arnheim, Rudolf

1966 The Myth of the Bleating Lamb. In Toward a Psychology of Art. Berkeley: University of California Press.

- Chalfen, Richard

1974 Film as Visual Communication: A Sociovidistic Study in Filmmaking. Ph.D. dissertation. University of Pennsylvania.

1975 Cinema Naivete: A Study of Home Moviemaking as Visual Communication. Studies in the Anthropology of Visual Communication 2(2): 87-103.

1979 Obituary of Sol Worth. American Anthropologist 81(1): 91-93.

- Chomsky, Noam

1957 Aspects of the Theory of Syntax. Cambridge: MIT Press.

- Grice, H. P.

1957 Meaning. The Philosophical Review 66(3).

- Gross, Larry

1973 Art as the Communication of Competence. UNESCO: Social Science Information 12(5):115-141.

1974 Modes of Communication and the Acquisition of Symbolic Competence. In Media and Symbols: The Forms of Expression, Communication, and Education (73rd Yearbook of the National Society for the Study of Education). D. R. Olson, ed. Pp. 56-80.

- Heider, Fritz

1958 The Psychology of Interpersonal Relations. New York: Wiley.

- Hymes, Dell, C. B. Cazden, and V. P. John, eds.

1972 The Functions of Language in the Classroom. New York: Teachers College Press. 
- Kelley, Harold

1967 Attribution Theory in Social Psychology. In Nebraska Symposium on Motivation. D. Levine, ed. Pp. 192-240. Lincoln: University of Nebraska Press.

- Kris, Ernst

1952 Psychoanalytic Explorations in Art. New York: International University Press. (Reprinted New York: Schocken, 1964.)

Malinowski, Bronislaw

1922 Argonauts of the Western Pacific. New York: E. P. Dutton and $\mathrm{Co}$.

- Spottiswoode, Raymond

1935 The Grammar of the Film. Los Angeles: University of California Press.

- Worth, Sol

1963 The Film Workshop. Film Comment 1(5):54-58.

1964 Public Administration and the Documentary Film. Prespectives in Administration (Journal of Municipal Association for Management and Administration, City of New York) 1:1925.

1965 Film Communication: A Study of the Reactions to Some Student Films. Screen Education July/August:3-19.

1966 Film as Non-Art: An Approach to the Study of Film. The American Scholar 35(2):322-334. (Reprinted in Perspectives on the Study of Film. J. S. Katz, ed. Boston: Little Brown, 1971, pp. 180-199).

1968 Cognitive Aspects of Sequence in Visual Communication. Audio Visual Communication Review 16(2):1-25.

1969 The Development of a Semiotic of Film. Semiotica 1(3):282-321.

1972a Toward the Development of a Semiotic of Ethnographic Film. PIEF Newsletter 3(3):8-12.

1972b Toward an Anthropological Politics of Symbolic Form. In Reinventing Anthropology. Dell Hymes, ed. Pp. 335-364. New York: Pantheon.

1974a The Use of Film in Education and Communication. In Media and Symbols: The Forms of Expression, Communication, and Education (73rd Yearbook of the National Society for the Study of Education). D. R. Olson, ed. Pp. 271-302.

1974b Seeing Metaphor as Caricature. New Literary History 6:195-209.

1975 Pictures Can't Say Ain't. Versus 12:85-108.

1978 Man Is Not a Bird. Semiotica 23(1/2):5-28.

1980 Margaret Mead and the Shift from Visual Anthropology to the Anthropology of Visual Communication. (Presented at a symposium honoring Margaret Mead, American Association for the Advancement of Science, 1976.) Studies in Visual Communication 6(1).

and John Adair

1967 The Navajo as Filmmaker: A Report of Some Recent Research in the Cross-Cultural Aspects of Film Communication. American Anthropologist 69(1):76-78.

1970 Navajo Filmmakers. American Anthropologist 72:9-34 (Reprinted in Worlds Apart: The Sociology of Education. London: Cassell, Collier, and MacMillan, 1975.)

1972 Through Navajo Eyes: An Exploration in Film Communication and Anthropology. Bloomington: Indiana University Press. Paperback edition, 1975

and Larry Gross

1974 Symbolic Strategies. Journal of Communication 24(4):27-39.

- Youngblood, G.

Expanded Cinema. New York: Dutton. 